\title{
संगीत में शिक्षण के उभरते नवीन रुछान
}

\author{
डॉ. बीनू डोगरा \\ वाइस प्रिंसिपल, पी.जी.जी.सी.जी, सैक्टर-11, चण्डीगढ़
}

संगीत मानव जाति के लिए कुदरत का एक अनुप उपहार है। समस्त संसार संगीत से न केवल ओत-प्रोत है अपितु सृष्टि का स्फुरण भी संगीत से ही अभिव्यक्त होता है। पक्षी के उड़ान का उनके कलरव से भान होता है, नदी की कल-कल से उसके बहाव का, झरने के झर-झर से पानी की बहुलता एवं उसके उत्थान का अभास होता है। गाय के रंभाने में भी एक ग्वाले को साहीतिक अनुभूति अभिव्यक्त होता हुआ वाणी तथा अन्य साधनां जो इतना स्वाभाविक व प्राकृतिक है, उसे औपचारिक शिक्षा में कैसे बाँध जाए। जब अन्य क्षेत्रों में शिक्षा अजीविका, जीवन-यापन और पेशे से जुड़ी है तो संगीत के क्षेत्रों में संगीत केवल संगीत के लिए ही क्यों?

इसमें भी औपचारिक सनद तथा पेशेवर शिक्षा का संगीत में करियर से जुड़ा होना चाहिए। बीसवीं शताब्दी का आरंभ केवल भारत के स्वातंत्राय युग का ही क्रान्ति काल नहीं है, अपितु संगीत शिक्षण को सृष्टि से भी एक अनोखी क्रान्ति का युग माना है। इससे पहले अनौपचारिक तौर पर ही गुरू-शिष्य परम्परा द्वार ही संगीत में शिक्षा के अवसर थे। परन्तु आज शिक्षण का क्षेत्र विस्तृत हो गया है, अधिक लोग संगीत को सुनते, समझते एवं सीखते हैं, जिसके फलस्वरूप संगीत की शिक्षा सबके लिए सुलभ हो गई है। किसी ने ठीक ही कहा है कि यदि किसी देश के शासन, देशवासियों के रहन सहन एवं संस्कृति का स्तर देखना चाहो तो उस देश के संगीत के स्तर को देख लो।

आज किसी विद्यार्थी को संगीत सीखने हेतु गुरू के घर रह कर उनकी सेवा करना अनिवार्य नहीं, उसे अलग-अलग घराने की विद्या एक ही मंच से सुनने को मिल जाती है। इसके अतिरिक्त विद्यालय, महाविद्यालय एवं विश्व-विद्यालय द्वारा शिक्षा का प्रावधान होने से एक तो संगीत शिक्षण में एकरूपता आई है और परिणाम के अवसर बढ़े हैं। संगीत के क्षेत्र में शिक्षा के प्रचार एवं प्रसार से कलाकारों को अपने जुनून को कायम रखने के साथ ही साथ उनके अजीविका के साध्न भी बढ़े 
हैं। inter-disciplinary प्रवेश का प्रयोग बढ़ रहा है वैसा ही संगीत के क्षेत्र में भी वांछनीय है सीमित की शिक्षा केवल मानवीसय संकारय तक ही सीमित न रख कर विज्ञान, वाणिज्य तथा प्रबन्ध पतकाया में भी प्रसारित होनी चाहिए होनी चाहिए। जिस प्रका-स्वास्थ देखभाल क्रय-विक्रय, कोश एवं खेल कूद में विशेष प्रकार की डण्ठण का प्रवाधन है, उसी प्रकार संगीत में भी प्रबन्ध की डिग्री होनी चाहिए। संगीत से जुड़ी संस्थाओं, प्रोग्राम आदि में उनके लिए रोजगार के अवसर खुलेंगें। इसी प्रकार संगीत के विभिन्न क्षेत्रों में क्रियात्मक प्रदर्शनकी औपचारिक शिक्षा का विधान होना चाहिए जिससे कलाकार अपनी प्रस्तुति को और अधिक निखार कर धन अर्जित करने की क्षमता को वदा सकेगा।

जन संचार अपने आप में बहुत बड़े उद्योग के रूप में विकसित हुआ है। फिल्म उद्योग के रूप में विकसित हुआ है। फिल्म उद्योग तथा दूरदर्शन दोनों आपस में जुड़े हैं, संगीत का इन क्षेत्रों के विकास में बहुत बड़ा योगदान है। आज कई जानी मानी फिल्म उद्योग तथा कला क्षेत्रा की हस्तियाँ अपने ज्ञान व अनुभव को सांझा करने तथा अगली पीढ़ियों को उसमें प्रशिक्षित करने के लिए आगे आई हैं नए-नए शिक्षण संस्थान खोले जा रहे है तथा उनमें विधिवत संगीत को शिक्षा के आयाम बढ़े हैं। प्रतिभा की पहचान तथा उसके विद्रोहन में ये संस्थाएं सशक्त भूमिका निभा रही है।

निस्संदेह कलाकार अपनी कला से परिपक्व होता है, कला की अभिव्यक्ति तथा उसके सवर्धन में, माध्यमों तथा मंच का विशेष योगदान होता है। संगीत के क्षेत्र में तथा शिक्षा में इन माध्यमों तथा मंचों का बड़ी तेजी से विकास हो रहा है। आज ये संस्थाएँ, गोष्ठियां कार्यशालाएँ, सेमीनार आदि को आयोजित कर संगीत शिक्षण के प्रचार-प्रसार में रचनात्मक भूमिका शिक्षण के प्रचार-प्रसार में रचनात्मक भूमिका निभा रही हैं। अनुसंधान की भी इस क्षेत्र में काफी गुंजाइश है। आने वाले समय में संगीत की शिक्षा पठन-पाठन, समीक्षा, अनुसंधान की रूपरेखा बदलने वाली है। समय के साथ इसे बदला जाता है तो अच्छा है, नहीं तो वक्त के आगे सबको झुकना पड़ता है।

यह तो नितांत सत्य है कि आज का संगीत विद्यार्थी अधिक चतुर और बुद्धिमान है। वह शिक्षित होने के कारण प्रत्येक बात को वैज्ञानिक कसौटी पर कस कर ही ग्रहण करता है। आज के समय में वह संगत शिक्षक, पार्श्व गायन, वादक, 
मंच कलाकार, गीतकार, धुनकार, लेखक, प्रकाशक, वाद्य निर्माता आदि के रूप में हमारे समाज में अर्थोपार्जन नहीं कर रहा है, अपितु चिकित्सा के व्यवसाय में भी संभावनाएं विकासोन्मुख है।

संगीत जितना अध्यात्मिकता से जुड़ा हुआ है उतना ही आज उस संसार से, जिसे हम भौतिक संसार कहते हैं। भूमण्डलीयकरण तथा वैश्वीकरण ने संगीत को शिक्षा के प्रचार एवं प्रसार को परिवर्तित कर दिया है। आज संगीत समय तथा स्थान की सीमाएं लाँघ कर अनन्त फैले क्षितिज को छूने को बेकरार है। Youtube, whatsapps, Internet तथा आधुनिक मंचों ने नए माध्यम तथा नई विद्याएँ ईजाद की हैं। सूचना क्रांति (T.T) ने संगीत के क्षेत्रा में आमूल-चूल परिवर्तन कर डाले हैं। अनतः हम कह सकते है कि पिछले कुछ वर्षो में विभिन्न संस्थाओं, सजग व्यक्तियों, पत्र-पत्रिकाओं, जनसंचार तथा इंटरनेट द्वार शिक्षण परम्परा को सचेत करने के प्रयत्न हो रहे हैं और यह अत्यन्त स्वागत योग्य है। 